\title{
Prevalence of Keratoconus in Refractive Surgery Population in Sohag Governorate
}

\author{
Adham S. Saro, Gamal A. Radwan, Osama A. Mohamed,Mortada A. Abozaid
}

\section{Abstract}

IntroductionKeratoconus $(\mathrm{KC})$ is a developmental anomaly in which the inferior or central portion of the cornea becomes thinner and bulges forward in a cone-shaped fashion as a result of noninflammatory thinning of the corneal stroma ${ }^{[\mathbf{1}, \mathbf{2}]}$.

The disease has its usual onset at puberty and, in many cases, progresses until the third to fourth decade of life, when it usually arrests ${ }^{[1]}$. Although a large proportion of keratoconic patients can be managed with contact lenses, an average of about $\mathbf{2 0 \%}$ of all keratoconic corneas require keratoplasty; some authors report markedly different surgical indication rates of 6.5 and 12 to $45 \% .^{[3-5]}$

Aim of the work: to study the prevalence of keratoconus in patients seeking refractive surgery to correct their refractive errors and to study common risk factors.

Patients and Methods: Two thousand eyes to 1202 patients (623 males and 579 females) coming for investigations for refractive surgery were randomly chosen in the period from April to October 2015. Screening -by Pentacam- was bilateral in $\mathbf{7 9 8}$ patients and unilateral in $\mathbf{4 0 4}$ patients.

Results: the resulting cases of keratoconus were 293 eyes (14.65\%) of 210 patients. Of those patients, males were 117 (165 eyes) (56.25\%) and females were 93 (128 eyes) (43.75\%).

Key words

\section{Keratoconus- Pentacam - prevalence- pachymetry- Keratometry}

\section{Introduction}

Keratoconus is a relatively common disorder with a reported prevalence ranging from $\mathbf{5 0}$ to 230 per 100,000. Keratoconus affects all races and both sexes equally with an onset around puberty ${ }^{[1]}$.

The reported prevalence of keratoconus varies widely depending upon the geographic location, diagnostic criteria used, and the cohort of patients selected. The first population-based study was done by Hofstetter $^{[6]}$ using a Placido disc and he reported an incidence of $\mathbf{6 0 0}$ per $\mathbf{1 0 0 , 0 0 0}$. The most commonly cited prevalence is $\mathbf{0 . 0 5 4 \%}$ in Minnesota, USA by Kennedy et al. ${ }^{[7]}$ who used scissors movement on retinoscopy and keratometry for diagnosis.

Environmental factors may contribute to the wide variation in prevalence. Geographical locations with plenty of sunshine and hot weather such as India ${ }^{[8]}$ and the Middle East ${ }^{[9]}$ have higher prevalence than locations with cooler climates and less sunshine such as $\operatorname{Denmark}^{[10]}$, Japan ${ }^{[11]}$, and Russia ${ }^{[12]}$. Ultraviolet light induced oxidative stress, which keratoconic corneas cannot handle well, may have a role to play.

The majority of recent papers ${ }^{[13,14]}$ indicate a preponderance of men over women with $\mathrm{KC}$. In a retrospective study conducted in Netherlands ${ }^{[15]}$, using data relating to over $\mathbf{1 0 0 , 0 0 0}$ contact lens wearers obtained from four university clinics and five contact lens centers between the years 1950 and 1986, the ratio of men to women was $\mathbf{0 . 5}$.

\section{Patients and Methods}

A prospective randomized clinical Study that was held in the Future center for LASIK and refractive surgery in Sohag.

Two thousand eyes to 1202 patients $(\mathbf{6 2 3}$ males and $\mathbf{5 7 9}$ females) coming for investigations for refractive surgery were randomly chosen in the period from April to October 2015. Screening was bilateral in $\mathbf{7 9 8}$ patients and unilateral in $\mathbf{4 0 4}$ patients.

The study was conducted on patients undergoing Pentacam, corneal topography as a routine screening before refractive surgery, thus confirmation or exclusion of keratoconus can be determined. 
Evaluation of the patient included:

- History taking (data collected included sex, age, history of consanguinity, medical ophthalmic problem e.g.; eye rubbing, allergic conditions by counting the approximate attacks of eye allergy per year)
- Then Pentacam was done to all cases, and the following data were obtained:

1. Pachymetry (thinnest corneal location)

2. Keratometry (the steepest and flattest meridian of the cornea and the average Keratometry)

3. The posterior surface elevation.

\section{Results}

A) Sex:The study was conducted on two thousand eyes of 1202 individuals (623 males and $\mathbf{5 7 9}$ females), with the resulting cases of keratoconus were 293 eyes (14.65\%) of 210 patients. Of those patients, males were 117 (165 eyes) (56.25\%) and females were 93 (128 eyes) (43.75\%). (Figure 1)

B) Consanguinity: It was positive in $\mathbf{4 2 \%}$ and negative in $\mathbf{5 8 \%}$ cases (Figure 2)

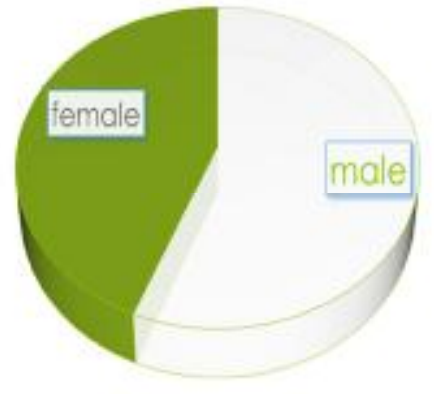

Fig. (1) Sex distribution of keratoconusFig.

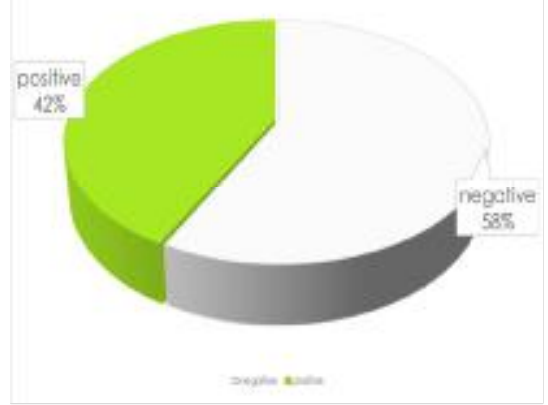

(2): distribution of keratoconus patientsin relation to their state of consanguinity.

C) Eye Allergy:

\begin{tabular}{|l|l|l|l|l|}
\hline \multicolumn{5}{|c|}{ No. of attacks of eye allergy per year. } \\
\hline & $\begin{array}{l}\text { Numbe } \\
\text { r }\end{array}$ & Mean \pm SD & Median & P value \\
\hline Male & 117 & $\mathbf{3 . 0 5} \pm \mathbf{2 . 3 6 3}$ & $\mathbf{3}$ & \multirow{0}{*}{0.119} \\
\hline Female & $\mathbf{9 3}$ & $\mathbf{2 . 4 2} \pm \mathbf{1 . 8 5 3}$ & $\mathbf{2}$ & \\
\hline
\end{tabular}

Table (1): Distribution of no. of attacks of eye allergy per year in relation to sex

E) Pachymetry:

\begin{tabular}{|c|c|c|c|c|c|}
\hline & \multirow[t]{2}{*}{ Mean \pm SD } & \multirow[t]{2}{*}{ Median } & \multicolumn{2}{|c|}{ 95\% Confidence Interval } & \multirow[t]{2}{*}{ P value } \\
\hline & & & lower bound & Upper bound & \\
\hline Male & $436.59 \pm 52.26$ & 445 & 428.53 & 444.64 & \multirow[t]{2}{*}{0.000} \\
\hline Female & $468.67 \pm 51.07$ & 463 & 459.77 & 477.56 & \\
\hline
\end{tabular}

Table (2): Distribution of pachymetry in keratoconus patients in relation to sex 
F) Keratometry:

\begin{tabular}{|l|l|l|l|}
\hline & Mean \pm SD & Median & P value \\
\hline Male & $48.36 \pm 6.17$ & 46.47 & \multirow{2}{*}{0.658} \\
\cline { 1 - 3 } Female & $48.08 \pm 4$ & 47.22 & \\
\cline { 1 - 3 } &
\end{tabular}

Table (3): Sex distribution related to Keratometry in keratoconus patients

G) Posterior surface elevation:

\begin{tabular}{|l|l|l|l|l|}
\hline & Mean \pm SD & Median & Range & P value \\
\cline { 1 - 4 } Male & $\mathbf{3 7 . 2 8} \pm 29.41$ & 28 & $7-120$ & \multirow{2}{*}{$\mathbf{2 8 1 0}$} \\
\cline { 1 - 4 } Female & $\mathbf{3 6 . 5 0} \pm \mathbf{2 4 . 5}$ & $\mathbf{3 0}$ & $\mathbf{9 - 1 1 5}$ & \\
\cline { 1 - 3 } & & & &
\end{tabular}

Table (4): Distribution of posterior surface elevation considering sex group

H) Grade of keratoconus:

\begin{tabular}{|c|c|c|}
\hline & Total no. of eyes & Percentage \\
\hline Subclinical & 138 & $47.1 \%$ \\
\hline Grade I & 103 & $35.2 \%$ \\
\hline Grade II & 23 & $7.8 \%$ \\
\hline Grade III & 29 & $9.9 \%$ \\
\hline Total & 293 & $100 \%$ \\
\hline
\end{tabular}

Table (5): Distribution of grade of keratoconic eyes and their percentage.

\section{Discussion}

The total prevalence of keratoconus entirely differed according to the geographical location; Gorskova $\mathrm{EN}^{[12]}$ described that the prevalence was 0.3 per $\mathbf{1 0 0 . 0 0 0}$ in Russia.In this study, the prevalence of the disease, including subclinical grade, in patients seeking refractive surgery was $\mathbf{2 9 3}$ out of $\mathbf{2 0 0 0}$ eyes $(\mathbf{1 4 . 6 5 \% )}$. This is considered unexpected high prevalence.

Concerning eye rubbing and its correlation with keratoconus, Boneham et al. ${ }^{[16]}$ found a strong relationship of frequent eye rubbing to development of keratoconus.

In this study, it has been proved that increased number of attacks of eye allergy and subsequently eye rubbing has its direct effect on development of keratoconus. Also, it has been documented that attacks of eye allergy increases with younger age group.

Concerning grade of keratoconus, subclinical keratoconus had the highest prevalence among all patients (138 eyes $=\mathbf{4 7 . 1 \%})$. Grade I came in the second ranking (103 eyes=35.2\%). Then grade III, II had the least prevalence with $\mathbf{9 . 9 \%}$ and $\mathbf{7 . 8 \%}$ percentages respectively.
This manner of distribution clarified higher prevalence in lower grades of keratoconus, with minimal number in advanced degrees. Its explanation may be because all these patients came to do investigations for refractive surgery, so patients having clinical criteria of advanced stages especially corneal scarring and hydrops, were excluded from the start as it was obvious that refractive surgery would be contraindicated.

\section{Summary}

Increased prevalence of keratoconus, nowadays is not an actual increase in number of cases, but it is due to increased liability of diagnosis of the disease by enhanced technologies including the Pentacam.

The prevalence of keratoconus was higher than expected (total prevalence was $\mathbf{( 1 4 . 6 5 \% )}$ )

In the study, higher percentage of patients were males, in the middle age group (25-35) years in both genders. However, grade of keratoconus was higher in younger age groups (15-25) years, who had higher prevalence of attacks of eye allergy. 


\section{References}

1.Krachmer JH, Feder RS, Belin MW, Keratoconus and related noninflammatory corneal thinning disorders. Surv Ophthalmol 1984;28:293-322.

2. Tuft SJ, Moodaley LC, Gregory WM, et al., Prognostic factors for the progression of keratoconus. Ophthalmology 1994;101:439-47.

3. A, Ihalainen, Clinical and epidemiological features of keratoconus genetic and external factors in the pathogenesis of the disease. Acta Ophthalmol Suppl 1986;178:1-64.

4. Gordon MO, Steger-May K, SzczotkaFlynn L, et al. , Baseline factors predictive of incident penetrating keratoplasty in keratoconus. Am J Ophthalmol 2006;142:923-30.

5. Ota R, Fujiki K, Nakayasu K., Estimation of patient visit rate and incidence of keratoconus in the 23 wards of Tokyo. Nihon Ganka Gakkai Zasshi 2002;106:365-72.

6. HW, Hofstetter, A keratoscopic survey of 13,395 eyes. . Am J Optom Arch Am Acad Optom. 1959;36:3-11.

7. Kennedy RH, Bourne WM, Dyer JA.,A 48-year clinical and epidemiological

study of keratoconus.Am J Ophthalmol. 1986;101:267-73.

8. Jonas JB, Nangia V, Matin A et al., Prevalence and associations of keratoconus in rural Maharashtra in central India. Am J Ophthalmol. 2009;148:760-5.
9. Assiri AA, Yousuf BI, Quantok AJ et al., Incidence and severity of keratoconus in Asir province, Saudi Arabia. $\quad \mathrm{Br} \quad \mathrm{J}$ Ophthalmol. 2005;89:1403-6.

10. Nielsen K, Hjortdal J, Aagard NE, Niels E. Incidence and prevalence of keratoconus in Denmark. Acta Ophthalmol Scand. 2007;85:890-2. .

11. Tanabe U, Fujiki K, Ogawa A, Prevalence of keratoconus patients in Japan. . Nihon Ganka Gakkai Zasshi. 1985;89:407-11.

12. Gorskova EN, Sevost'ianov EN, Epidemiology of keratoconus in the Urals. Vestn Oftalmol. 1998;114:3840.

13. L. Lim, R. H. Wei, W. K. Chan, and D. T. H. Tan, Evaluation of keratoconus in Asians: role of Orbscan II and Tomey TMS-2 corneal topography. The American Journal of Ophthalmology, vol. 143, no. 3, pp. 390-400, 2007.

14. A. M. Bawazeer, W. G. Hodge, and B. Lorimer, Atopy and keratoconus: a multivariate analysis. British Journal of Ophthalmology, vol. 84, no. 8, pp. 834-836, 2000.

15. F. P. Eggink, A. J. L. G. Pinckers, and E. P. van Puyenbroek, Keratoconus, a retrospective study. Contact Lens Journal, vol. 16, pp. 204-306, 1998.

16. Boneham, C. W. Mcmonnies and G. C., Keratoconus, allergy, itch, eyerubbing and hand-dominance. Clinical and Experimental Optometry, vol. 86, no. 6, pp. 376-384, 2003. 